Enas TM Al-Jwary BDS, MSc (Asst Lec.)

\section{Factors Affecting on Permanent Defor- mation of Orthodontic Arch wires (An In vitro Study)}

Dept of Pedod, orthod, and Prev Dentistry

College of Dentistry, University of Mosul

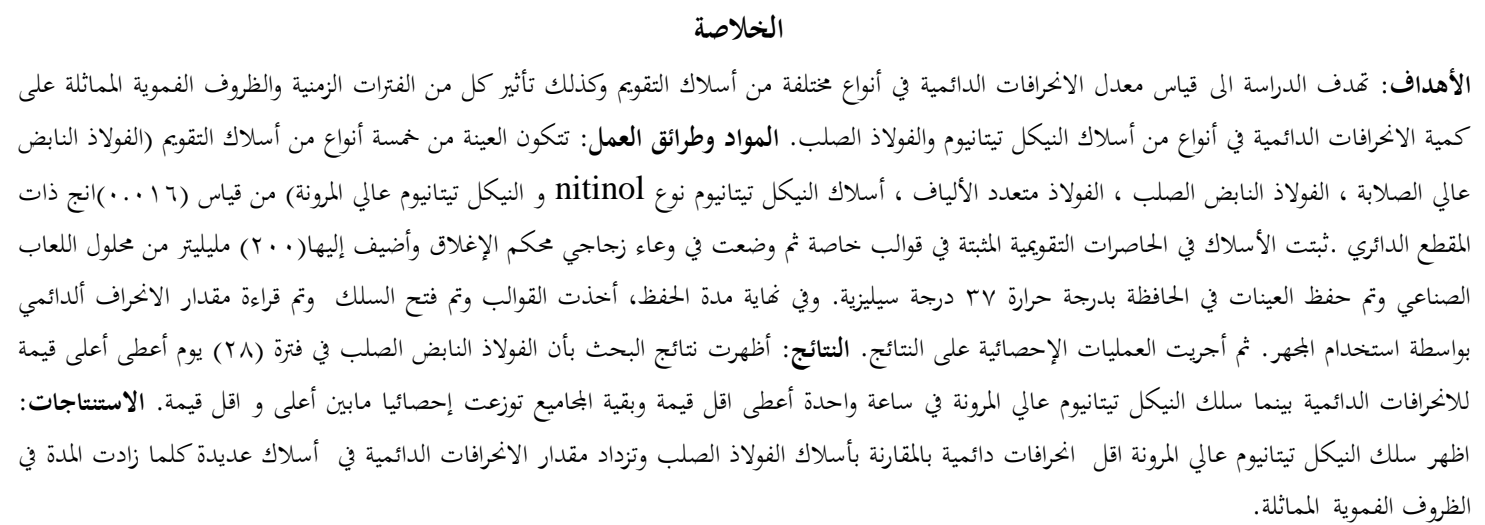

\title{
ABSTRACT
}

Aims: To measure the amount of permanent deformation of different types of orthodontic arch wires and to study the effect of both time interval and simulated oral environment on amount of permanent deformation of different types of nickel titanium and stainless steel orthodontic arch wires. Materials and Methods: The sample consisted of five types of orthodontic arch wires (extra spring hard stainless steel , spring hard stainless steel, multi strand stainless steel ,nitinol nickel titanium and super elastic nickel titanium), 0.016 inch of round section were deflected into orthodontic brackets fitted in acrylic models put in a closely packed glass container and $200 \mathrm{ml}$ artificial saliva added to them and the samples stored in incubator at $37^{\circ} \mathrm{C}$. At the end of incubation period, the acrylic block take and the wire deactivated and the amount of permanent deformation measured by using Stereo microscope. The results were subjected to the descriptive statistics and to the ANOVA and Duncan's Multiple Range Analysis Tests to detect the changes among these groups. Results The findings of the present study showed that spring hard stainless steel wires at 28 days gave rise to the highest mean values of permanent deformation, while the super elastic wires at $1 \mathrm{hr}$ gave rise to the lowest one. The remaining groups distributed on statistical levels of significant difference $(P \leq 0.05)$ between the upper and lower levels. Conclusions: The super elastic nickel titanium wires exhibited better spring back characteristics and less permanent deformation than the stainless steel. Several wires increased deformation as deflection time increased in simulated oral environment.

Key word: orthodontic wires ,permanent deformation.

Al-Jwary ETM. Factors Affecting on Permanent Deformation of Orthodontic Arch wires (An In vitro Study) Al-Rafidain Dent J. 2011; 11(2): 317-322.

Received: $7 / 4 / 2010$

Sent to Referees: $8 / 4 / 2010$

Accepted for Publication: 3/6/2010

\section{INTRODUTION}

Certain metallic alloys can restore its original shape after being submitted to unusually large strains. ${ }^{(1)}$ Ideal aligning arch wires should be able to move teeth with light, continuous forces over prolonged periods of time and long distances. Light orthodontic forces produce the same amount of tooth movement as heavier forces and are physiologically acceptable. ${ }^{(2,3)}$ For the initial leveling and aligning stages of orthodontic treatment, practitioners are still using traditional arch wires made from stainless steel (SS) or conventional nickel titanium (NiTi) that is martensite stabilized. Additionally, pseudoelastic (so-called super elastic) NiTi alloys are engineered to provide a constant force during tooth movement. ${ }^{(3,4)}$ Alternative leveling products include Multistranded stainless steel wires that deliver ultra-low forces ${ }^{(5)}$ and esthetically pleasing products 
such as glass-fiber composites and polymer-coated wires. ${ }^{(6)}$

The ideal properties of leveling arch wires include high strength, low stiffness to deliver low forces per unit of deactivation, and high range(spring back) to maximize activations. ${ }^{(5)}$ Clinically, it is the unloading or deactivation forces that produce orthodontic tooth movement. In other words, when the stress is removed, the shape memory properties allow the phase transformation to reverse, and, as the wire returns to its original shape, it generates tooth movement. ${ }^{(8,9)}$

In the typical implementation of an orthodontic arch wires elastic deformation of the wire produces a force that is used to move a tooth into more desirable position .As the tooth slowly moves, the wire spring back towards a relaxed configuration. The relationship between force (or stress) and the flexural displacement (or stain)of the wires is linear within the elastic limit of the constituent material, ${ }^{(10)}$ However some materials are often characterized by viscoelastic or time dependent stress -strain behavior. Clinically, this be- havior would cause decrease in the amount of spring back that would be available for tooth movement. ${ }^{(1)}$

\section{MATERIALS AND METHODS}

A variety of 0.016 -inch round section orthodontic wires were tested and the sample comprised of five types of orthodontic arch wires include (extra spring hard stainless steel, spring hard stainless steel, multi strand stainless steel, nitinol nickel titanium and super elastic nickel titanium. ${ }^{(12)}$ The specimens' numbers used in this study were (250), 10 wires for each wire types and time interval. The specimens' length of the arch wires used in this study was $50 \mathrm{~mm}$. $^{(13)}$

These wires engaged in the acrylic models in which a three brackets fixed with a light cure composite resin (XRV Herculite). The standard edgewise stainless steel brackets $(0.018 \times 0.030$ inch $)$ fixed in about five $\mathrm{mm}$ inter proximally and three $\mathrm{mm}$ occlusogingival discrepancy between the center bracket and the adjacent one as in Figure (1).

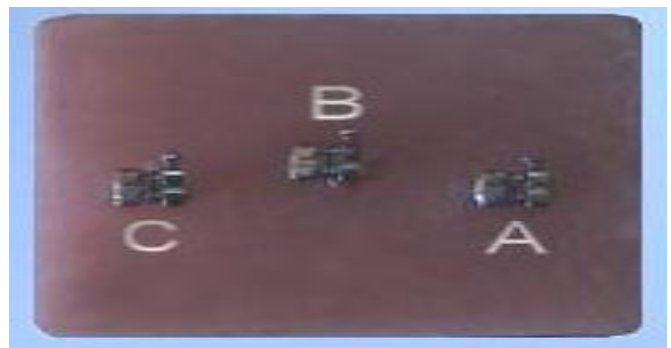

Figure (1): Acrylic Block on which a Standard Stainless steel Brackets Fixed.

This distance determines the amount of displacement of wires. This method was described by Burstone et al. ${ }^{(14)}$ and Quintto et $a l^{(15)}$ and Van et al. ${ }^{(4)}$

After that the specimen of each wire type was taken and secured to brackets on acrylic block by ligature elastics, so the wire subjected to three $\mathrm{mm}$ displacement, ten blocks made and then these blocks put in a closely packed glass container and filled with $200 \mathrm{ml}$ of artificial saliva and the samples store in incubator at $37^{\circ} \mathrm{C}$.

By the same procedure other samples are prepared for each wire type and for each time interval, so each glass container corresponds to one time interval and one type of wire. ${ }^{(14-16)}$
The formula used for preparation of artificial saliva solution was described by Barrett et al.. ${ }^{(17)}$ and this includes:

$0.4 \mathrm{gm} \mathrm{NaCl}, 1.21 \mathrm{gm} \mathrm{KCl}, 0.78 \mathrm{gm}$ $\mathrm{NaH}_{2} \mathrm{PO}_{4} .2 \mathrm{H}_{2} \mathrm{O}, 0.005 \mathrm{gm} \quad \mathrm{Na}_{2} \mathrm{~S} .9 \mathrm{H}_{2} \mathrm{O}, 1$ gm urea $\left[\mathrm{CO}\left(\mathrm{NH}_{2}\right)_{2}\right]$ and $1000 \mathrm{ml}$ distilled and deionized water.

The $\mathrm{PH}$ of the artificial saliva was adjusted by using PH meter to $6.75 \pm 0.15$ with $10 \mathrm{~N}$ sodium hydroxide. The $\mathrm{PH}$ value was coincided with that reported for human saliva.

The replacement of the artificial saliva solution was performed every week to avoid saturating the artificial saliva medium with corrosion product. ${ }^{(17)}$

At end of each incubation periods 
(1hr,24hr ,72hr, 7 days, 28 days), the wire specimens were taken to study the amount permanent deformation of wires.

Measurement Method :

The measurement of the amount of permanent deformation done in technical institute of mosul, departments of technology, laboratory of metals by using Stereo microscope (Zeisis,Co.,Germany) (Figure 2).

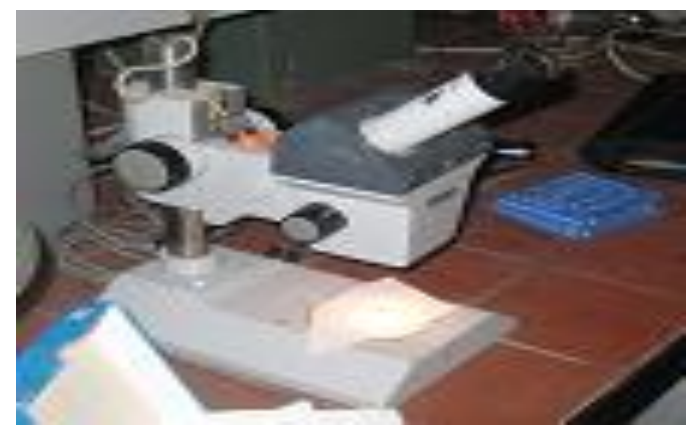

Figure (2): Stereo microscope (Zeisis,Co.,Germany)

The lens of the microscope degreed in micron and the magnification of microscope was set at (20X). Then the measurement was recorded and divided to obtain the amount of permanent deformation in millimeter.
The amount of permanent deformation measured from the line drawn from the center of bracket $\mathrm{A}$ and the center of bracket $\mathrm{B}$ and the inner border of the wires (Figure 3).

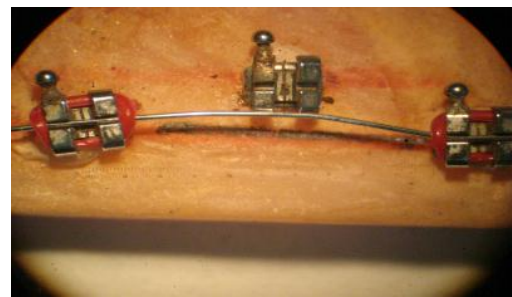

Figure (3): Measurement method under stereo microscope

At the end of each incubation periods, each acrylic block take and the wire disengaged from bracket $\mathrm{C}$ by removal of ligature elastic, then the acrylic block put under the lens of microscope and measurement done by measuring the distance between the line drawn from the center of the bracket A to the center of the bracket B and the inner border of the wire. This distance represented the permanent deformation ${ }^{(14,16,18)}$ Figure (3).

\section{RESULTS}

The descriptive statistics that include mean, standard deviation, minimum and maximum values of the amounts of permanent deformation in millimeter are listed in Table (1) .

The findings of the present study showed that spring hard stainless steel wires at 28 days of incubation showed to the highest mean values of permanent deformation, while the super elastic nickel titanium wires at $1 \mathrm{hr}$ of incubation period gave rise to the lowest one.

The remaining groups were distributed on statistical levels between the higher and lower level of mean, minimum and maximum values.

The one way analysis of variance (ANOVA) for the permanent deformation values of wires showed significant difference at $(P<0.001)$ among the groups as in Table (2).

The result of Duncan's multiple range test (Table 3) showed that the spring hard stainless steel wires at 28 days had the highest rate of permanent deformation with significant difference $(P \leq 0.05)$ with other types of wires, while the super elastic nickel titanium wires at $1 \mathrm{hr}$ gave rise to the lowest one with significant difference $(P \leq 0.05)$ from other groups. The remaining groups distributed on statistical levels of significant difference $(P \leq 0.05)$ between the upper and lower levels. 
Table (1): The descriptive statistic of the amounts of permanent deformation in $\mathrm{mm}$ (means, minimum, maximum values and standard deviation).

\begin{tabular}{cccccc}
\hline Types of wires & $\begin{array}{c}\text { Time in- } \\
\text { tervals }\end{array}$ & mean & Std.deviation & Minimum & maximum \\
\hline Extra spring & $1 \mathrm{hr}$ & 1.339 & 2.614 & 1.29 & 1.35 \\
hard stainless & $24 \mathrm{hr}$ & 1.380 & 2.479 & 1.35 & 1.40 \\
steel & $72 \mathrm{hr}$ & 1.882 & 1.549 & 1.88 & 1.88 \\
& $1 \mathrm{wk}$ & 2.086 & 3.098 & 2.05 & 2.11 \\
spring hard & $28 \mathrm{day}$ & 2.249 & 2.409 & 2.24 & 2.29 \\
stainless steel & $1 \mathrm{hr}$ & 1.294 & 5.164 & 1.29 & 1.29 \\
& $24 \mathrm{hr}$ & 1.300 & 4.216 & 1.30 & 1.30 \\
& $72 \mathrm{hr}$ & 1.784 & 4.216 & 1.76 & 1.80 \\
& $1 \mathrm{wk}$ & 2.050 & 4.216 & 2.05 & 2.05 \\
Multistranded & $28 \mathrm{day}$ & 2.294 & 4.216 & 2.29 & 2.29 \\
stainless steel & $1 \mathrm{hr}$ & 0.1176 & 4.216 & 0.12 & 0.12 \\
& $24 \mathrm{hr}$ & 0.37 & 2.582 & 0.35 & 0.40 \\
& $72 \mathrm{hr}$ & 0.8113 & 2.493 & 0.76 & 0.82 \\
Nitinole nickel & $1 \mathrm{wk}$ & 0.8235 & 4.216 & 0.82 & 0.82 \\
titanium & $28 \mathrm{day}$ & 0.9410 & 4.216 & 0.94 & 0.94 \\
& $1 \mathrm{hr}$ & 0.117 & 4.216 & 0.12 & 0.12 \\
& $24 \mathrm{hr}$ & 0.3 & 4.216 & 0.3 & 0.3 \\
& $72 \mathrm{hr}$ & 0.47 & 4.216 & 0.47 & 0.47 \\
Super elastic & $1 \mathrm{wk}$ & 0.5294 & 4.216 & 0.53 & 0.53 \\
nickel titanium & $28 \mathrm{day}$ & 0.5882 & 4.216 & 0.59 & 0.59 \\
& $1 \mathrm{hr}$ & 0.088 & 1.033 & 0.09 & 0.09 \\
& $24 \mathrm{hr}$ & 0.24 & 2.108 & 0.20 & 0.25 \\
& $72 \mathrm{hr}$ & 0.2936 & 8.433 & 0.29 & 0.29 \\
& $1 \mathrm{wk}$ & 0.3529 & 4.216 & 0.35 & 0.35 \\
& $28 \mathrm{day}$ & 0.4012 & 2.222 & 0.36 & 0.41 \\
\hline
\end{tabular}

Std: standard deviation, hr: hour, wk: week.

Table (2): (ANOVA) for Demonstrated permanent deformation of Different Orthodontic Wires Types.

\begin{tabular}{cccccc}
\hline & Sum of Square & df & Mean Square & F- value & $P$ \\
\hline Between groups & 131.888 & 24 & 5.495 & & \\
Within groups & 4.943 & 225 & & 25016.339 & $P<0.001$ \\
Total & 131.937 & 249 & 2.197 & & \\
\hline
\end{tabular}

Table (3): The Duncan Multiple Analysis Rang Test.

\begin{tabular}{cccccc}
\hline Types of wires & \multicolumn{5}{c}{ Time intervals } \\
\hline Extra spring hard stainless steel & $\mathbf{1 h r}$ & $\mathbf{2 4 h \mathbf { h r }}$ & $\mathbf{7 2 h r}$ & $\mathbf{1 w k}$ & $\mathbf{2 8 d a y}$ \\
spring hard stainless steel & $\mathrm{h}$ & $\mathrm{g}$ & $\mathrm{e}$ & $\mathrm{c}$ & $\mathrm{b}$ \\
Multistranded stainless steel & $\mathrm{i}$ & $\mathrm{i}$ & $\mathrm{f}$ & $\mathrm{d}$ & $\mathrm{a}$ \\
Nitinole nickel titanium & $\mathrm{t}$ & $\mathrm{p}$ & $\mathrm{k}$ & $\mathrm{k}$ & $\mathrm{j}$ \\
Super elastic nickel titanium & $\mathrm{t}$ & $\mathrm{r}$ & $\mathrm{n}$ & $\mathrm{m}$ & $\mathrm{l}$ \\
\hline
\end{tabular}

hr: hour, wk: week, Different letters mean significant difference $(P \leq 0.05)$. 


\section{DISCUSSIONS}

This study focused on one mechanical property (permanent deformation) as a function of time. The results are relevant to the practicing orthodontist. The results of the present study showed that the spring hard stainless steel wires displayed a significantly higher amount of permanent deformation than other types of wires due to the mechanical properties of stainless steel wires which characterized by high strength, high stiffness, low flexibility and low spring back action. This finding is similar to the result obtained by Hudgins et $a l^{(16)}$ who found that the stainless steel arch wires exhibited less spring back characteristics and more permanent deformation than other types of wires. A similar result was reported by Tang et al ${ }^{(19)}$ who found that the stainless steel wires suffered a higher deformation than other types of wires. The present study also showed the super elastic nickel titanium wires deformed with limited amount when compared with the nitinol and stainless steel wires due to high spring back and low stiffness and high flexibility, This result agreed with Burstone et al. ${ }^{(14)}$

All types of wires showed a time dependent deformation, due to the effect of simulated oral environment on mechanical properties of wires, Similarly in oral environment, all wires suffered degradation of their mechanical properties. The spring hard stainless steel wire at 28 days demonstrated a significantly higher amount of permanent deformation comparing with the super elastic nickel titanium wires at $1 \mathrm{hr}$ incubation time which demonstrated a less amount of a time dependent deformation and this result come in agreement with Hudgins et al ${ }^{(16)}$ who found that all nickel titanium arch wires exhibited better spring back characteristics and less permanent deformation than the stainless steel. Also Barrows ${ }^{(20)}$ found that distortion of wires increased $7 \%$ after 8 weeks when compared to the $1 \mathrm{hr}$ time interval, also Sarmad ${ }^{(21)}$ found that as the exposure time of the orthodontic arch wire in the oral environment is increased, the amount of loss of the mechanical properties could be increased, Also Eliades and Christoph $^{(22)}$ found that the environmental conditions of the oral cavity ,might alter the morphologic, structural and compositional characteristic and mechanical properties of orthodontic alloys and polymers.

The super elastic nickel titanium wires exhibited less permanent deformation than the original nitinol wire. This result was in agreement with Burstone et $a l^{(14)}$ and Miura et al ${ }^{(23)}$ who found Chinese nickel titanium wire and Japanese nickel titanium wires exhibited less permanent deformation than did nitinol.

In this study, The nitinol wires show time dependent deformation and this result was similar to a research obtained by Lopez et al ${ }^{(24)}$ who found that nitinol experienced time dependent deformation. also Harris et al ${ }^{(25)}$ studied mechanical properties of nitinol after 1, 2 and 4 months of deformation and found degradation of mechanical properties. On other hand this result was disagreed with Andreasen and Morrow ${ }^{(26)}$ who found that no permanent deformation was observed when nitinol wire was bended for less than 1 hour.

\section{CONCLUSIONS}

The super elastic nickel-titanium wires exhibited a better spring back characteristics and less permanent deformation than the stainless steel wires. Several wires increased deformation as time increased in simulated oral environment. From a clinical perspective, this decrease might be clinically relevant because the unloading forces of the wire produce the orthodontic tooth movement. Therefore, in patients mouth ,the increased deformation could contribute to prolonged orthodontic treatment.

\section{REFERENCES}

1. Ana M F, Paulo M, Vicente B. Lowcycle fatigue life of superelastic NiTi wires. International Journal of Fatigue. 2009; 31: 751-758.

2. Evans TJ, Durning P. Aligning archwires, the shape of things to come?-a fourth and fifth phase of force delivery. Br J Orthod 1996;23:269-75.

3. Santoro M, Nicolay OF, Cangialosi TJ. Pseudoelasticity and thermoelasticity of nickel-titanium alloys: a clinically oriented review. Part I: temperature transi- 
tional ranges. Am J Orthod Dentofacial Orthop 2001;119:587-593.

4. Van A, Cornelis A, Prem P, Kleverlaan R, Kuitert B, Albert J. Effect of long-term repeated deflectionson fatigue of preloaded superelastic nickeltitanium archwires. Am J Orthod Dentofacial Orthop. 2008;133(2): 269-276.

5. Brian K, Kusy R. Elastic properties of alternative versus single stranded leveling archwires. Am J Orthod Dentofacial Orthop. 2002; 122: 528-541.

6. Vittorio C, Maria F, Alessandro L, Andrea S, Pekka K, cand V. Force levels of fiber-reinforced composites and orthodontic stainless steel wires: A 3point bending test. Am J Orthod Dentofacial Orthop. 2008; 133 (3): 410413.

7. Proffit WR. Contemporary orthodontics. 3rd ed. St Louis: Mosby. 2000; p. 528-529

8. Alexander S, Ripa L. Effects of selfapplied topical fluoride preparations in orthodontic patients. Angle Orthod. 2000;70: 424-430.

9. Mary P, Richard J, Katherine S. Effect of fluoride prophylactic agents on the mechanical properties of nickeltitanium-based orthodontic wires. Am J Orthod Dentofacial Orthop .2005; 127: 662-669.

10. Kusy R.P. A review of contemporary arch wires ,their properties and characteristics. Angle Orthod. 1997; 67: 197208.

11. Scott W, Kusy P. Stess relaxation and recovery behavior of composite orthodontic archwires in bending .European J orthodontic. 2000; 221: 1-12.

12. Peter D, Peter S, James A, Peter $\mathrm{H}$. Load-deflection characteristics of superelastic nickel-titanium orthodontic wires .Am J Orthod Dentofacial Orthop. 2002; 12 1(5): 483-495.

13. Taneja P, Duncanson MG, Khajotia SS, Nanda RS. Deactivation force deflection behavior of multistranded stainless steel wires. Am J Orthod Dentofac Orthop. 2003 ; 124(1): 61-68.

14. Burstone C, Qin B, Morton J. Chinese NiTi wire: A new orthodontic alloy. Am J Orthod. 1985; 87(6): 445-452.
15. Quintto C, Cal-Neto J, Menezes L, Elias C. Force-deflection properties of initial orthodontic archwires. World $J$ Orthod. 2009; 10 (1): 29-32.

16. Hudgins J ,Michael D, Leslie C .The effect of long term deflection on permanent deformation of nickel titanium arch wires. Angle orthodontic .1989; 60 (4): 283-288.

17. Barrett RD, Bishara SE, Janice KQ. Biodegradation of orthodontic appliances: part I- Biodegradation of nickel and chrominum in vitro. Am J Orthod Dentofac Orthop. 1993; 103 (1): 8-14.

18. Wong E, Borland D, West V. Deformation of orthodontic arch wires over time. Aust Orthod J.1994; 13 (3): 152158.

19. Tang G, Liu K, Cao H, Lu J, Zhang C. Orthodontic wires in a simulated oral environment :change in mechanical properties. Shanghai Kou Qiang Yi Xue. 1997; 6 (3) sep: 159-162.

20. Barrowes JK. Arch wire flexibility and deformation. J Clin Orthod. 1982; 16 (12): 803-811.

21. Sarmad S. Evaluation of the mechanical properties of orthodontic arch wires in dry and wet environment (An in vitro study). M.Sc. Thesis. College of dentistry, University of Mosul 2006.

22. Eliades T, Christoph B. Intraoral aging of orthodontic materials: The picture we miss and its clinical relevance. Am J Orthod Dentofac Orthop. 2005; 127 (4): 405-412.

23. Miura F ,Mogi M ,OhuraY ,Hamanaka $H$.The super_elastic properties of the Japanese NiTi alloy wire of use in orthodontics. Am J Orthod Dentofac Orthop. 1986; 90: 1-10.

24. Lopez I ,Goldberg A, Burstone J. Bending characteristics of nitinol wire. Am J Orthod. 1979; 75: 569-574.

25. Harris E, Newman S, Nicholson J. Nitinol archwire in a simulated oral environment: Changes in mechanical properties. Am J Orthod Dentofac Orthop. 1988; 93(6): 508-513.

26. Andreasen G, Morrow R. Laboratory and clinical analysis of nitinol wire. Am J Orthod. 1978;73 (2): 142-151. 